RESEARCH AND PRACTICE

\title{
Growing Fit: Georgia's model for engaging early care environments in preventing childhood obesity
}

Kelsey McDavid, $\mathrm{MPH}^{1}$, Catalina Piedrahita ${ }^{2}$, Patricia Hashima, $\mathrm{PhD}^{1}$, Emily Anne Vall, $\mathrm{PhD}^{1}$, Christi Kay, MEd ${ }^{3}$, and Jean O’Connor, JD, MPH, DrPH ${ }^{1,4}$

${ }^{1}$ Georgia Department of Public Health, Atlanta, GA; ${ }^{2}$ U.S. Centers for Disease Control and Prevention, Atlanta, GA; ${ }^{3}$ HealthMPowers, Inc., Atlanta, GA; and ${ }^{4}$ Emory University, Atlanta, GA

\begin{abstract}
Background: In the United States, one in three children is overweight or obese by their fifth birthday. In Georgia, 35 percent of children are overweight or obese. Contrary to popular belief, children who are overweight or obese are unlikely to outgrow their weight status as adults, making early childhood an essential time to address weight status. An estimated 380,000 Georgia children attend early care and education environments, such as licensed child care centers, Head Start, and pre-kindergarten programs, which provide an opportunity to reach large numbers of children, including those at risk for obesity and overweight.
\end{abstract}

Methods: To address this opportunity, the Georgia Department of Public Health, Georgia Shape - the Governor's Initiative to prevent childhood obesity, and HealthMPowers, Inc., created the Growing Fit training and toolkit to assist early childhood educators in creating policy, systems, and environmental changes that support good nutrition and physical activity. This report, the first related to this project, describes the training and its dissemination between January and December 2015.

Results: A total of 103 early childcare educators from 39 early childcare education centers (22 individual childcare systems) from 19 counties in Georgia were trained. Fifteen systems completed a pre and post-test assessment of their system, demonstrating slight improvements. Training for an additional 125 early childcare education centers is planned for 2016.

Conclusions: Lessons learned from the first year of the training include the need for more robust assessment of adoption and implementation of policy, systems, and environmental changes in trained centers.

Key Words: nutrition, weight status, physical activity, obesity, early care, children, education

\section{INTRODUCTION}

Overweight and obesity are generally the result of too few calories expended for the amount of calories consumed. This caloric imbalance is influenced by the food environment, including access to fresh fruits and vegetables and the availability of high sugar and high-fat foods (CDC, 2015). In the United States, one in three children is overweight or obese by their fifth birthday (CDC, 2015 (2)). In Georgia, the numbers are higher. Approximately 35 percent of Georgia adolescents are overweight or obese, and more than 10 percent of children 2-5 years old are obese (CDC, 2012). Childhood obesity increases the risk of being obese as an adult (CDC, 2013).

Between 2008 and 2011, one U.S. territory and 18 states, including Georgia, experienced a decline in obesity rates among preschoolers from low-income families (CDC, 2013) Despite this progress, the state has a higher percentage of children who are overweight or obese than the national average (Robert Wood Johnson and Trust for America's Health, 2015). The topic of early childhood obesity calls for ongoing attention of public health professionals, educators, policymakers, and communities in Georgia.

Obesity is closely correlated with income. Low-income children, particularly those who live in households that experience food insecurity, are at high risk of being overweight or obese (Robert Wood Johnson and Trust for America's Health, 2015). Georgia's poverty rate among children under age 5 (31.2 percent) is significantly higher than the national average of 25.6 percent (Census, 2014). Georgia is also a racially diverse state, with approximately 38 percent of the population identifying as a race other than white, as compared with about 22 percent in the U.S. overall (Census, 2015). Racial and ethnic disparities in weight status become evident in childhood and Blacks and Hispanics are more likely than Whites to be obese as adults (Ogden, 2015).

In Georgia, preventing and controlling overweight and obesity in early childhood is therefore of critical public health importance. Childhood obesity contributes to the development of lifelong and costly chronic diseases, such as 
type 2 diabetes, high blood pressure, arthritis and sleep apnea (Robert Wood Johnson and Trust for America's Health, 2015). In addition, for children, there is an association between diet, physical activity and academic performance (CDC, 2014). Poorly nourished, overweight, sedentary, and/or hungry children tend to have weaker academic performance and to score lower on standardized achievement tests (CDC, 2012). Good nutrition and regular physical activity support children's physical health, academic achievement, and emotional well-being (CDC, 2012).

An estimated 380,000 Georgia children attend early care and education (ECE) environments, such as licensed child care centers, Head Start, and pre-kindergarten programs, which provide an opportunity to reach large numbers of children, including those at risk for obesity and overweight (Child Policy Partnership, 2008). In Georgia's ECE environments, creating a healthy food environment and developing healthy eating and physical activities at a young age can contribute to a healthier population; reduce obesity and chronic disease; and allow children to develop, grow, learn, and have a healthy future. Results of a study testing an intervention to train caregivers in best practices to improve nutrition and physical activity in 24 Georgia preschools (Lyn et al., 2011) provided an opportunity to promote healthy weights among children and to demonstrate improvements in the nutrition environment (Lyn, 2011). Further, exposure of children to programs such as farm-topreschool has a positive effect on fruit and vegetable consumption (Izumi, et al. 2015). Therefore, these ECE programs present an opportunity to implement model practices regarding healthy eating and physical activity. Implementing a wellness policy focusing on healthy preschool time demonstrates that the organization recognizes the importance of a healthy lifestyle and supports an environment conducive to healthy lifestyle choices. (Larson, 2011 and Larson, 2011(2)).

To address this opportunity, the Georgia Department of Public Health (DPH) Chronic Disease Prevention Section, in collaboration with Georgia Shape, HealthMPowers, Inc. and the Department of Early Care and Learning (DECAL) developed the Growing Fit Kit: Wellness Policies in Georgia's Early Care Environment and an associated Growing Fit training, intended to guide early care settings in establishing and/or improving polices relating to nutrition and physical activity (O'Connor, 2015). The toolkit and training also support licensed centers in moving toward achievement of DECAL's Quality Rated standards and provide a source of continuing education credits required for staff in licensed early care settings.

The premise of the training is that comprehensive wellness policies can improve children's health if the staff members and parents are aware of the policy and understand how to implement it on a day-to-day basis. A wellness policy is a written document or documents that state the specific approaches promoted and followed to create and support the healthiest possible environment. Day-to-day practices to implement the policy are necessary in creating a healthy environment for young children and in preparing them to develop healthy eating and physical activity habits. Caregivers are also role models, and wellness policies in early childhood environments can support teachers and staff seeking to achieve a healthy lifestyle.

In the Growing Fit model, staff of ECE centers are trained by use of a step-by-step process, "the ABC's of wellness policy." The first step is to (A) Assess the needs of the center. After conducting a self-assessment, the ECE center next (B) Builds a plan that outlines when the policy will be implemented, who will hold others responsible, and what the policy statement will include. The policy is intended to be a dynamic document that is built and improved over time. The plan is intended to help centers celebrate their strengths and identify weak areas to build a plan for improvement. Strengths in their initial wellness policy and areas for improvement are identified so that those items can be included in the policy at a later date, when the setting is ready to make those changes. The final step of this process is to (C) Create the policy for implementation and later evaluate its use. After evaluation, it may be determined that some policies need to be added or revised (O'Connor, 2015).

\section{METHODS}

Between January and December 2015, the Growing Fit Kit was disseminated and a four-hour version of training was administered by DPH and HealthMPowers, Inc. to more than 39 early care settings and 105 early care educators and health promotion staff, primarily in areas of Georgia that have a high burden of obesity.

Targeted geographic areas were selected to address needs in terms of health outcomes and capacity to accomplish the work. Areas of highest need included the Southeast Health District, the South Health District, and the Coastal Health District. Participating ECE centers were recruited primarily through outreach by individuals in the community, such as local health department officials. Training sessions were administered first in the Southeast Health District as regional workshops and reached more than 25 ECE centers. Additionally, the training was conducted at a conference held by the Georgia Association on Young Children and in the LaGrange Health District in partnership with Tanner Health System. All ECE centers with staff planning to attend were requested to have the ECE center director participate, along with two additional staff, educators, and/or nutrition personnel.

The Growing Fit Tool Kit contains the following material: 1) an explanation of the importance of a wellness policy; 2) a self-assessment tool to evaluate current policies and practices; 3) success stories from other early care and learning settings; 4) a list of healthy eating and physical activity resources; 5) a planning document with suggestions and examples for writing the policy; and 6) for use in the classroom, supplies that reinforce the issues discussed in the training, such as posters, a music CD for physical activities, and books about fruits and vegetables for young children. The four-hour training featured didactic and experiential learning opportunities concerning early care nutrition and 
physical activity; a personalized planning opportunity for improvement of the wellness policy of the director's facility; and, for use in the early care setting, a package of resource items, including music and books about nutrition and physical activity.

For all training sessions, participants who were directors of ECE centers were asked to complete an ECE Information Form and the Let's Move! Child Care Checklist Quiz (Checklist). The ECE Information Form captured demographic information for children enrolled in the center or centers the director was overseeing at the time. The Checklist is a measurement tool recommended by CDC for assessing the degree to which ECE environments and policies support strategies for promoting healthy eating and physical activity; it is being used by state grantees across the United States. The Checklist was developed by CDC in collaboration with the University of North Carolina at Chapel Hill and Nemours, a non-profit children's health organization.

The Checklist is a 15-item questionnaire designed to be completed by a person, such as the ECE center director, with knowledge of the setting's environment and policies. Respondents are asked about frequency of physical activity, frequency of serving certain types of foods, screen time, availability of drinking water, style of serving meals, and opportunities for breast feeding in the center. The questionnaire asks respondents to rate their performance on a scale of 1 to 4 . (1= Unable to work on meeting this best practice now; $2=$ Ready to start on meeting this best practice; $3=$ Making progress on meeting this best practice; and 4=Fully meeting this best practice).

At completion of the face-to-face session, participants of the training, regardless of position or affiliation with ECE centers/programs, were offered the opportunity to evaluate the training. The evaluation tool consisted of Likert-type scale items and open-ended questions, and is further described below.

\section{RESULTS}

Between January 1, 2015 and December 31, 2015 five separate Growing Fit trainings were held; 122 individuals were trained. Of these, 19 were observers associated with public health programs or universities, and 103 were early educators. Titles of participants included center director, teacher, training director, cook, after school coordinator, and parent-community engagement director. The early educators represented 39 childcare locations across 22 systems from 19 counties. The types of the childcare systems varied. Five were Head Start systems with multiple sites; two were YMCA locations; and others were in private or non-profit settings (Table1 and Figure 1).
Table 1. ECE Sites by System and Number of People Trained

\begin{tabular}{|c|c|c|}
\hline ECE System & ECE Count & \# Trained \\
\hline 1 & 1 & 2 \\
\hline 1 & 2 & 1 \\
\hline 2 & 3 & 7 \\
\hline 3 & 4 & 15 \\
\hline 4 & 5 & 2 \\
\hline 5 & 6 & 8 \\
\hline 6 & 7 & 6 \\
\hline 7 & 8 & 2 \\
\hline 8 & 9 & 5 \\
\hline 9 & 10 & 5 \\
\hline 9 & 11 & 1 \\
\hline 9 & 12 & 1 \\
\hline 9 & 13 & 1 \\
\hline 9 & 14 & 1 \\
\hline 9 & 15 & 1 \\
\hline 9 & 16 & 1 \\
\hline 9 & 17 & 1 \\
\hline 9 & 18 & 2 \\
\hline 9 & 19 & 1 \\
\hline 9 & 20 & 1 \\
\hline 9 & 21 & 1 \\
\hline 9 & 22 & 1 \\
\hline 9 & 23 & 1 \\
\hline 9 & 24 & 1 \\
\hline 9 & 25 & 1 \\
\hline 10 & 26 & 3 \\
\hline 11 & 27 & 5 \\
\hline 12 & 28 & 1 \\
\hline 13 & 29 & 6 \\
\hline 14 & 30 & 1 \\
\hline 15 & 31 & 3 \\
\hline 16 & 32 & 1 \\
\hline 17 & 33 & 1 \\
\hline 18 & 34 & 1 \\
\hline 19 & 35 & 1 \\
\hline 20 & 36 & 2 \\
\hline 21 & 37 & 2 \\
\hline 22 & 38 & 2 \\
\hline 22 & 39 & 2 \\
\hline
\end{tabular}


Figure 1. ECE sites trained on Growing Fit in 2015 in Georgia

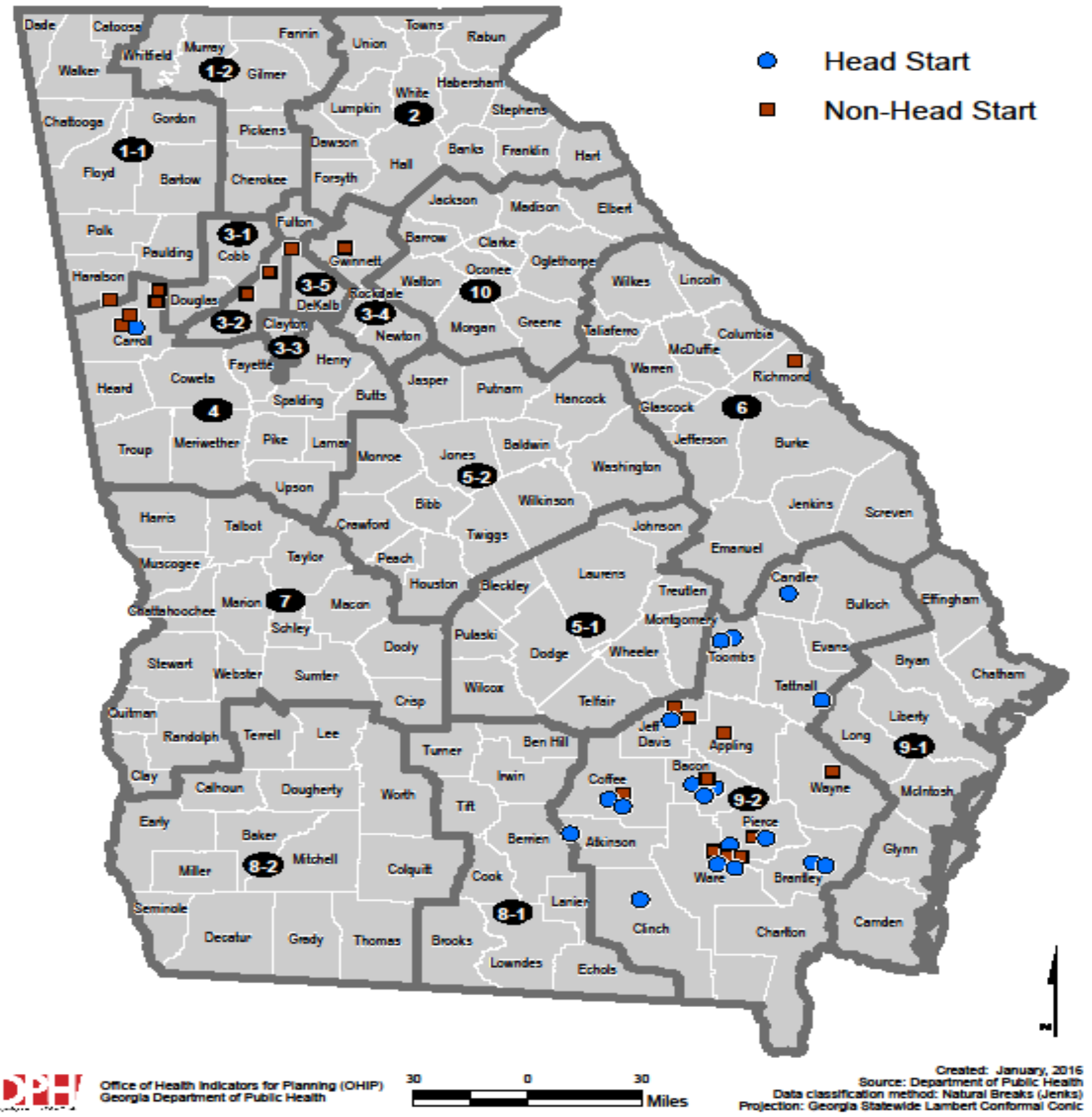


Of the 22 systems that participated in Growing Fit, personnel from 15 completed the Checklist, and seven attended the training. The center director was unavailable to complete it. Of the 15, representatives of nine completed the Checklist pre- and post-training; two completed the Checklist pre-training but failed to complete the posttraining test. The remaining four completed the Checklist pre-training, but since they were less than six months posttraining, they had not yet been offered the opportunity to complete the post-test Checklist.

The items measured on the Checklist included the following: 1) Drinking water is visible and available inside and outside for self-serve (N1); 2) $100 \%$ fruit juice is limited to no more than 4-6 oz. per day per child and parents are encouraged to support this limit (N2); 3) Sugary drinks, including fruit drinks, sports drinks, sweet tea, and soda are never offered (N3); 4) Children 2 years and older are served $1 \%$ or skim/non-fat milk (unless otherwise directed by the child's health provider) (N4); 5) Fruit (not juice) and/or vegetable is served to toddlers and preschoolers at every meal. (French fries, tater tots, and hash browns do not count as vegetables.) (N5); 6) French fries, tater tots, hash browns, potato chips, or other fried or pre-fried potatoes are offered to toddlers and preschoolers no more than once a month (Baked fries are acceptable.) (N6); 7) Chicken nuggets, fish sticks, and other fried or pre-fried forms of frozen and breaded meats or fish are offered to toddlers and preschoolers no more than once a month (N7); 8) All meals to preschoolers are served family style so that children are encouraged to serve themselves with limited help (N8); 9) Preschoolers, including children with special needs, are provided with 120 minutes or more of active play time every day, both indoor and outdoor (for half-day programs, 60 minutes or more is provided for active play every day)
(P1); 10) At child care, we strive to limit total screen time (e.g., TV and DVD viewing, computer use) to no more than 30 minutes for preschoolers per week or never, and we work with parents/caregivers to ensure that children have no more than 1-2 hours per day (for half-day programs, we strive to limit total screen time to no more than 15 minutes per week or never) (P2); 11) Parents of preschoolers are provided screen time reduction and/or media literacy education such as special programs, newsletters, or information sheets, two or more times per year (P3); 12) Toddlers, including children with special needs, are provided with 60-90 minutes or more of active play time every day, both indoor and outdoor (for half-day programs, 30 minutes or more is provided for active play every day) (P4); 13) Screen time for toddlers and infants is limited to no more than 3-4 times per year or is never allowed (P5); 14) For breastfeeding or pumping, breastfeeding mothers are provided access to a private room, other than a bathroom, with appropriate seating and privacy (N9); and, 15) Short supervised periods of 'tummy time' are provided for all infants, including those with special needs several times each day (P6).

Overall mean pre-test Checklist scores for ECE centers ranged from 2.40 to 3.29 , with 4 being the highest score; overall mean post-test scores ranged from 2.90 to 3.32, with the greatest increase from pre- to post-test in a single school of 0.59 (Table 2). The statistical significance of the difference between the pre- and post-test mean scores could not be reliably calculated due to the small sample size and missing data. Some ECE centers reported a small decrease in mean score, which may be attributable to a better understanding among the participants of the true nature and significance of the questions subsequent to the training.

Table 2. Pre and Post-Test Overall Mean Scores by Early Care System

\begin{tabular}{|c|c|c|c|}
$\begin{array}{c}\text { Early Childcare } \\
\text { System }\end{array}$ & $\begin{array}{c}\text { Pre Test Overall Mean } \\
\text { Score }\end{array}$ & Post Test Mean Overall Score & $\begin{array}{c}\text { Variance Between Mean Pre } \\
\text { and Post Test Scores }\end{array}$ \\
\hline $\mathbf{1}$ & 2.88 & 3.25 & 0.37 \\
\hline $\mathbf{2}$ & 2.88 & 3.21 & 0.33 \\
\hline $\mathbf{3}$ & 3.29 & 3.32 & 0.03 \\
\hline $\mathbf{4}$ & 3.15 & 3.19 & 0.04 \\
\hline $\mathbf{5}$ & 3.06 & - & - \\
\hline $\mathbf{6}$ & 3.00 & - & - \\
\hline $\mathbf{7}$ & 3.12 & 3.03 & -0.09 \\
\hline $\mathbf{8}$ & 2.40 & 2.99 & 0.59 \\
\hline $\mathbf{9}$ & 2.71 & 3.11 & 0.40 \\
\hline $\mathbf{1 0}$ & 3.13 & 2.90 & -0.23 \\
\hline $\mathbf{1 1}$ & 2.93 & 2.96 & 0.03 \\
\hline $\mathbf{1 2}$ & 3.06 & - & - \\
\hline $\mathbf{1 3}$ & 3.00 & - & - \\
\hline $\mathbf{1 4}$ & 2.76 & - & - \\
\hline $\mathbf{1 5}$ & 3.12 & - & \\
\hline
\end{tabular}


Mean scores across all respondents were high on all variables, except "Chicken nuggets, fish sticks, and other fried or pre-fried forms of frozen and breaded meats or fish are offered to toddlers and preschoolers no more than once a month (N7)" and "All meals to preschoolers are served family style so that children are encouraged to serve themselves with limited help (N8).” The next lowest scoring items were "Parents of preschoolers are provided screen time reduction and/or media literacy education such as special programs, newsletters or information sheets, 2 or more times per year (P3)" and "Breastfeeding mothers are provided access to a private room for breastfeeding or pumping, other than a bathroom, with appropriate seating and privacy (N9)” (Table 3).

Table 3. Pre- and Post-Test Mean Scores by Item

\begin{tabular}{|c|c|c|c|c|c|c|c|c|c|}
\hline Pre-Test & Mean & Min & Max & Sdev & Post-Test & Mean & Min & Max & Sdev \\
\hline R-N1 & 3.79 & 3.00 & 4.00 & 0.37 & R-N1 & 3.56 & 3.00 & 4.00 & 0.50 \\
\hline R-N2 & 3.80 & 2.00 & 4.00 & 0.96 & R-N2 & 3.78 & 3.00 & 4.00 & 0.45 \\
\hline R-N3 & 3.73 & 1.00 & 4.00 & 1.12 & R-N3 & 4.00 & 4.00 & 4.00 & 0.00 \\
\hline R-N4 & 4.00 & 4.00 & 4.00 & 0.00 & R-N4 & 3.89 & 3.00 & 4.00 & 0.39 \\
\hline R-N5 & 3.73 & 1.00 & 4.00 & 1.12 & R-N5 & 4.00 & 4.00 & 4.00 & 0.00 \\
\hline R-N6 & 3.57 & 1.00 & 4.00 & 1.12 & R-N6 & 3.50 & 1.00 & 4.00 & 1.19 \\
\hline R-N7 & 3.07 & 1.00 & 4.00 & 1.22 & R-N7 & 3.22 & 1.00 & 4.00 & 1.08 \\
\hline R-N8 & 1.92 & 1.00 & 4.00 & 1.00 & R-N8 & 3.25 & 1.00 & 4.00 & 1.14 \\
\hline R-P1 & 3.73 & 1.00 & 4.00 & 1.12 & R-P1 & 4.00 & 4.00 & 4.00 & 0.00 \\
\hline R-P2 & 3.93 & 3.00 & 4.00 & 0.37 & R-P2 & 3.88 & 3.00 & 4.00 & 0.40 \\
\hline R-P3 & 3.29 & 2.00 & 4.00 & 0.91 & R-P3 & 3.50 & 2.00 & 4.00 & 0.80 \\
\hline R-P4 & 4.00 & 4.00 & 4.00 & 0.00 & R-P4 & 4.00 & 4.00 & 4.00 & 0.00 \\
\hline R-P5 & 3.75 & 3.00 & 4.00 & 0.51 & R-P5 & 3.78 & 3.00 & 4.00 & 0.45 \\
\hline R-N9 & 3.18 & 1.00 & 4.00 & 1.39 & R-N9 & 3.25 & 1.00 & 4.00 & 1.22 \\
\hline R-P6 & 3.85 & 3.00 & 4.00 & 0.52 & R-P6 & 4.00 & 4.00 & 4.00 & 0.00 \\
\hline
\end{tabular}

At the conclusion of their training, participants evaluated the training by responding to eight questions with a Likert-type scale and seven open-ended questions. The Likert-type scale included the following items: how would you rate the training overall; clarity of presentation; quality of materials used; how clearly the objectives of the training were defined; how knowledgeable the trainer was on the subject matter; how well the trainer answered the questions; if the training added to the participant's level of knowledge; and if the training provided the participant with new skills that he or she can apply to his or her work.

After the first three of the five training sessions that took place in 2015, only one of these questions with Likert-type scale responses remained for the final two training sessions. The rating of the training overall question was retained in all evaluations throughout the year. It scored a 4.95, with 5 being the highest possible score. The other questions were dropped due to a consistent response of "Excellent" for all other fields by all training participants. After the first three training sessions of the year, five of the seven open-ended questions were dropped as well after the first three training sessions of the year. The questions dropped were "What topic did you find most interesting;" "What topic did you find most useful;" "How do you hope to change your activities or approaches as a result of this training;" "Please list topic(s) you think you'll need more support or information to implement;" and, "How can the training

session be improved?” Most participants responded with "None" or did not respond to these questions.

The two open-ended questions that remained throughout the 2015 Growing Fit trainings were "What suggestions do you have for future training topics?" and "Any other comments or feedback?” Participants reported that they found the session useful, stating "brilliant, enjoyable, fun, and informative all at the same time" and "I loved this training and learned so much.” Many attendees reported an interest in seeking further training or wanting more of their fellow staff members to attend the training at a future date. Constructive feedback was sparse, but included a suggestion that more activities for classroom exercises would be beneficial. One of the directors commented, "I wish I could get this type of training for my teachers to help get them on board quicker and understand the 'why'!"

\section{DISCUSSION}

Despite the overall high score on the Child Care Checklist, 2 of 15 respondents who completed the pre-training test (13\%) scored 2 ("Ready to get started on meeting this best practice") or below ("Unable to work on meeting this best practice right now") on item N8 ("All meals to preschoolers are served family style so that children are encouraged to serve themselves with limited help.") and 3 of 15 respondents (20\%) scored 2 or below on item N9 ("Breastfeeding mothers are provided access to a private 
room for breastfeeding or pumping, other than a bathroom, with appropriate seating and privacy.”) For 2016, DPH is considering addressing these two topics in our technical assistance that is provided. Furthermore, DPH plans to use the pre-training test data to prepare additional technical assistance to support ECE centers seeking to enhance their nutrition and physical activity practices and policies.

To address how trainees-center staff or director-can disseminate and implement what they have learned, the program also is considering incorporating, into the Growing Fit training, effective ways to communicate to the director or staff ways in which to change their ECE policies and/or to create supplemental training (via webinar or other forms of technical assistance) to support trainees in promoting implementation of policies that encourage healthy eating and physical activity.

The initial cohorts engaged in the training may be early adopters with an interest in the topics of childhood obesity, nutrition, and physical activity. For 2015, all participating ECE centers scored high on the Child Care Checklist even before attending the Growing Fit training. It is possible that ECE centers whose staff voluntarily attend training to achieve a more health-promoting child care environment are often already implementing practices to encourage healthy eating and physical activity. In fact, the initial results reflect only small changes in self-assessed performance on the Child Care Checklist items. In 2016, DPH plans to reach out to ECE centers in counties and areas of the state with a high prevalence of childhood obesity to train and provide technical assistance in enhancing the nutrition and physical activity practices and policies of those centers. Further, to understand the impact of the training on policies and environments, more evaluation is needed, as are comparisons with results from other models of early educator training on physical activity and nutrition being tested in Georgia.

\section{CONCLUSIONS}

For ECE providers in Georgia, the initial response to the training opportunity suggests a need for training on nutrition and physical activity for young children. The Growing Fit training program was designed to reach more than 380,000 children in early care settings in Georgia. In its first year, the trainings reached the intended audience-both in the targeted geographic areas as well as types of early care and education environments and by various staff types. The training was well-received by these participants. In 2016, the program is planned to train an additional 100 centers and associated staff. The potential reach of the Growing Fit training is promising for promoting awareness of the importance of nutrition and physical activity in ECE settings, and the training is providing a basis for additional work with ECE settings.

However, the Checklist results suggest that there are areas in which ECE centers whose staff participate in the training could benefit from additional in-depth technical assistance or training, either through modification of the Growing Fit materials or other professional development opportunities.
For example, many participants rated their centers low on implementation of breastfeeding-related best practices before and after the Growing Fit training. The topic of lactation support is not addressed in depth in the Growing Fit training and toolkit, in part due to other available training on this subject.

Further, the Checklist data collected from participating centers do not provide insight into whether centers adopted or implemented the policies developed during the training. Further evaluation, including collection of additional data, such as the texts of center policies or observation of the center environment after the training, beyond the federallyrecommended Childcare Checklist, is needed to assess longterm changes in ECE policies and environments and in staff knowledge and attitudes. Finally, the outcomes of Growing Fit need to be compared with other emerging models for this type of training being offered in Georgia.

\section{Acknowledgments}

This manuscript and the development and implementation of Growing Fit were supported by funds from the State of Georgia and CDC Cooperative Agreement number NU58DP004801-03-03. The authors also wish to acknowledge the support and engagement of the early care and learning centers that participated in the initial training as well as staff in the South, Southeast, and Coastal Health Districts of Georgia. And, finally the authors wish to acknowledge the support of DPH Commissioner Brenda Fitzgerald, MD, Yvette Daniels, JD and J. Patrick O'Neal, MD, as well as Chronic Disease Prevention staff Shalonda Freeman, PhD, MPH, Kenneth Ray, MPH, and Kia Powell-Threets, MS for their support of the project. The findings and conclusions in the report are those of the authors and do not necessarily represent the official position of the State of Georgia or CDC.

\section{References}

Centers for Disease Control and Prevention [CDC]. (2012). Health \& Academics Data and Statistics. Retrieved from Division of Adolescent and School

Health: http://www.cdc.gov/healthyschools/health and academi cs/data.htm

Centers for Disease Control and Prevention [CDC]. (2012). State of Georgia Physical Activity, Nutrition and Obesity Profile. Retrieved

from http://www.cdc.gov/obesity/stateprograms/fundedstates/pd f/georgia-state-profile.pdf

Centers for Disease Control and Prevention [CDC] (2014). Health and Academic Achievement. Retrieved from Adolescent and School

Health: http://www.cdc.gov/healthyyouth/health_and_academics /pdf/health-academic-achievement.pdf

Centers for Disease Control and Prevention [CDC] (2015). Childhood Obesity Facts. Retrieved from Division of Nutrition, Physical Activity, and

Obesity: http://www.cdc.gov/healthyschools/obesity/facts.htm

Centers for Disease Control and Prevention [CDC]. (2015). Childhood Obesity Causes \& Consequences. Retrieved from Division of Nutrition, Physical Activity, and Obesity: http://www.cdc.gov/obesity/childhood/causes.html Centers for Disease Control and Prevention. Vital Signs: Obesity Among Low-Income, Preschool-Aged Children - United States, 2008-2011. Morbidity and Mortality Weekly Report. 9 Aug 2013; 62(31):629-634. Retrieved from: http://www.cdc.gov/mmwr/preview/mmwrhtml/mm6231a4.htm ?s_cid=mm6231a4_w 
Child Policy Partnership (2008). Economic Impact of the Early Childcare and Education Industry in Georgia. Georgia Childcare Association. Retrieved

from http://www.georgiachildcare.org/Resources/Documents/ge orgiaeconomicimpactstudy.pdf

Izumi, B., Eckhardt, C., Hallman, J., Herro, K., \& Barberis, D. (2015). Harvest for Healthy Kids Pilot Study: Associations between Exposure to a Farm-to-Preschool Intervention and Willingness to Try and Liking of Target Fruits and Vegetables among Low-Income Children in Head Start. Journal of the Academy of Nutrition and Dietetics, 115.

Larson N, Ward DS, Neelon BS, Story M. (2011). Preventing obesity among preschool children: how can child-care settings promote healthy eating and physical activity? Princeton (NJ): Robert Wood Foundation.

Larson N, Ward DS, Neelon SB, Story M. (2011). What role can child-care settings play in obesity prevention? A review of the evidence and call for research efforts. J Am Diet Assoc;111(9):1343-62.

Lyn R, Maalouf J, Evers S, Davis J, Griffin M. (2011). Nutrition and Physical Activity in Child Care Centers: the Impact of a Wellness Policy Initiative on Environment and Policy Assessment and Observation Outcomes, 2011. Prev Chronic Dis;10:120232.
O’Connor J, Kay C, Piedrahita CA, Scott S, Vall EA. (2014). Georgia Department of Public Health Growing Fit Kit. Retrieved

from https://dph.georgia.gov/sites/dph.georgia.gov/files/related files/site page/growing fit kit v4.pdf

Ogden CL, Carroll MD, Fryar CD, Flegal KM. Prevalence of obesity among adults and youth: United States, 2011-2014. NCHS data brief, no 219. Hyattsville, MD: National Center for Health Statistics. 2015. Retrieved from: http://www.cdc.gov/nchs/data/databriefs/db219.htm

Robert Wood Johnson and Trust for America’s Health. (2015). State of Obesity in Georgia. Retrieved from State of Obesity: Better Policies for a Healthier America 2015. Retrieved from http://stateofobesity.org/

U.S. Census Bureau [Census] (2014). Small Area Income and Poverty Estimates. Retrieved from: http://www.census.gov/did/www/saipe/data/interactive/saipe.ht ml?s_appName=saipe\&map_yearSelector=2014\&map_geoSele ctor=aa_c

U.S. Census Bureau [Census] (2015). Quick Facts Table Comparing the United States and Georgia. Retrieved from: http://www.census.gov/quickfacts/table/PST045215/00,13 